\title{
Dos sonetos bubosos entre Mateo Alemán y Vicente Espinel. Edición crítica y estudio
}

\author{
Two syphilitic sonnets between Mateo Alemán \\ and Vicente Espinel. Critical edition and study
}

Luis Gómez Canseco

Universidad de Huelva

RESUMEN: En el catálogo de las obras compuestas por Mateo Alemán, casi siempre se olvida o se prescinde del soneto «Si ese tu inútil cuerpo, brazos, piernas», escrito en respuesta a otro de Vicente Espinel sobre la sífilis. Este trabajo edita y estudia ambos textos.

Palabras clave: Mateo Alemán, Vicente Espinel, poesía, bubas.

ABSTRACT: The catalogue of works composed by Mateo Alemán almost always leaves out the sonnet «Si ese tu inútil cuerpo, brazos, piernas», written in response to another sonnet about syphilis by Vicente Espinel. The present essay critically edits and studies both texts.

Keywords: Mateo Alemán, Vicente Espinel, poetry, syphilis.

De entre los pocos versos castellanos y latinos que del autor de Guzmán de Alfarache nos han llegado, el soneto "Si ese tu inútil cuerpo, brazos, piernas" ha pasado tan desapercibido para la crítica alemaniana que casi nunca se relaciona entre sus obras. El poema fue compuesto como juguete literario y respuesta jocosa a otro soneto, "De un ébano sutil, dos bellas piernas", cuya autoría se asigna a Vicente Espinel y que narra en primera persona las desdichas de un amante buboso, al que Alemán responde en un fino ejercicio retórico, utilizando rimas idénticas a las del soneto original. La edición y el estudio de ambos textos es la razón principal de estas notas. 
El primer testimonio conocido de ambas composiciones se recoge en el cartapacio de Pedro Penagos de la Biblioteca de Palacio, que comenzó a compilarse en $1593^{1}$. Si de la réplica no conocemos más testimonio antiguo que el de Penagos, el soneto de Espinel nos ha llegado en diez copias manuscritas más, que plantean un considerable problema en torno a su atribución. Junto a la propuesta de Penagos, el códice Rime spagnuole de la Biblioteca Riccardiana de Florencia lo asigna a "Padilla", mientras que la copia de la Hispanic Society lo vincula a Luis de Góngora y el manuscrito 4067 de la Biblioteca Nacional de España lo incluye entre las Obras manuscriptas de don Francisco de Quevedo y Villegas. En los demás testimonios de mano, el soneto consta como anónimo, aunque en el manuscrito 2244 de la misma Biblioteca Nacional se anota en el margen con letra posterior: "En el Parnaso de Sedano VIII, p. 402, atribuido a $\mathrm{P}^{\mathrm{o}}$ Laýnez", pues, en efecto, Juan Joseph López de Sedano aprovechó el soneto para cerrar el volumen VIII de su Parnaso español, impreso en 1774, y se lo asignó a Pedro Laínez.

La opción de Quevedo ha sido definitivamente descartada por la crítica (Alonso Veloso, 2010: I, 136-173)2 ${ }^{2}$, mientras que la atribución a Góngora resultaba difícilmente sostenible, ya que el soneto aparecía añadido de otra mano al final del volumen y sin ningún otro argumento que contribuyera a su defensa (Góngora, 1981: 628). Por su parte, la candidatura de Padilla se sustenta en un escueto "Soneto de Padilla", que pudiera aludir al poeta jiennense Pedro de Padilla, amigo de Cervantes y activo hasta finales del siglo $\mathrm{XVI}^{3}$. Hay, sin embargo, razones suficientes para descartar esta atribución, pues Padilla transitó por territorios poéticos bien distintos y, para cuando el poema hubo de componerse, andaba en otras lides literarias y personales, acordes con su condición de carmelita profeso desde 1584. Más allá de esos datos biográficos, resulta sospechoso que, precisamente en ese mismo códice Rime spagnuole, de la Riccardiana, el soneto venga incrustado entre varias composiciones vinculadas a Vicente Espinel: "Soneto de Espinel a la pasión de Cristo", "Soneto de Lope de Vega a Espinel" y "Soneto de Spinelo" (179r-181r). La alternativa de Laínez se mantuvo con la única autoridad de López de Sedano en la edición que de su poesía hizo Antonio Marín Ocete (1950: 361), aun cuando solo un año después Joaquín de Entrambasaguas (1950: 215-217 y 1951: 130-134) descartara ese prohijamiento, inclinándose por la figura de Espinel. A esa misma opción se

\footnotetext{
${ }^{1}$ Cfr. Cortijo Ortiz (1995: 21) y Cartapacio de Pedro de Penagos (2012: 25). Agradezco que Abraham Madroñal muy generosamente me haya permitido consultar la edición del cartapacio de Penagos antes de que llegara a ver la luz como libro.

${ }^{2}$ Cfr. asimismo Quevedo (1969: I, 67); Sánchez Alonso (1927: 123-146 y 387-431); y Carreira (2002: 150).

${ }^{3}$ En torno a la vida y obra de Padilla, véase Bajona Oliveras (1955-1956: 231-241); Padilla (2007 y 2009); y Valladares Reguero (2008 y 2010).
} 
han atenido los más recientes editores de la poesía del rondeño, José Lara Garrido (1985: 29-30) y Gaspar Garrote (1990: 191-192), que han reconocido en el soneto la mano de Espinel por su proximidad a textos como la Sátira a las damas de Sevilla, la Canción de una dama a su honra o la descripción cómica que el poeta hizo de sí mismo en su epístola A don Juan Téllez de Girón, marqués de Peñafiel.

Los sonetos "De un ébano sutil..." y "Si ese tu inútil cuerpo..." se explican como gesto de una amistad entre Espinel y Alemán, que pudo iniciarse en Sevilla hacia 1578, en Madrid entre 1584 y 1586, cuando el sevillano ejercía como contador real, o incluso hacia 1591 y de nuevo en la corte, donde una vez más se había asentado Espinel y donde vino a publicar sus Rimas ${ }^{4}$. Ese trato familiar queda confirmado por el interesantísimo epigrama latino que Espinel compuso para los preliminares de la Primera parte de Guzmán de Alfarache (1599), "Ad Guzmanum Alfarache, Vincentii Spinelli epigrama”, y que curiosamente también se presenta como un diálogo cómico entre Spinellus y Guzman (Alemán, 2012: 22-23). De hecho, el comienzo de la transmisión manuscrita del envío y la respuesta apunta a una composición no muy anterior a 1592, poco antes de que Penago hiciera su copia y justo cuando Alemán comenzaba a esforzarse por encontrar un hueco en el Parnaso hispánico.

Ambos poemas han de entenderse como una parodia del petrarquismo y del platonismo, en la que se alteran grotescamente la belleza de la dama y la actitud de un enamorado inclinado más bien a la lujuria. En el soneto que Espinel remite, el sujeto de la enunciación describe puntualmente la fealdad de una mujer, por la que declara una pasión carnal irresistible 5 . Esa voz acude a la primera persona en un recurso ficticiamente autobiográfico, pues aquí el yo — que no aparece como sujeto de la acción amorosa hasta el verso 13 - tiene un carácter simultáneamente cómico y ejemplar. Hasta ese momento, se van superponiendo sujetos gramaticales que sirven al poeta para enhebrar una descripción de las distintas partes de la dama. En el retrato resultante, se conjugan la fealdad natural de la señora y las lesiones provocadas por la sífilis y por los remedios aplicados para su curación, que han terminado por convertirla en un ser aún más deforme. No en vano el copista de $H$ dejó patente la resolución del enigma planteado, titulando el poema $A$ una dama bubosa en quintaesencia.

López de Sedano (1774, XLVII) fue el primero en señalar el carácter paródico del poema de Espinel respecto a los modelos petrarquistas, desta-

\footnotetext{
${ }^{4}$ Para las fechas en que esa amistad pudo comenzar, véase Haley (1994: 35-36) y Garrote Bernal (2001: 21-23).

${ }^{5}$ Gaspar Garrote ha anotado la posibilidad de que no sea el amante, sino la propia dama la que hable de sí misma en el texto: "Creo que también puede interpretarse que es la propia dama la que se autodescribe y que todo el soneto es su propia predicación, procedimiento ficticio que Espinel empleará en la Canción de una dama a su honra" (1990: 192).
} 
cando "la extravagancia del asunto como opuesto al sistema de todos los poetas, pues habiendo sido uno de sus principales cuidados - y el que ha dado tanta materia a sus versos - el de pintar a sus damas en el extremo de la hermosura, sacando de quicio a la misma naturaleza para acomodarlas todos los símiles, imposibles y atributos más quiméricos de la belleza, nuestro autor, por la contraria, parece que anduvo buscando las imágenes y símiles no menos quiméricos e hiperbólicos del horror y de la fealdad para la composición de las partes de una mujer"6. De hecho, toda la descripción que abre este discurso poético sigue una pauta marcada por textos de una tradición neopetraquista que arranca con el conocido soneto "Mentre che l'aureo crin v'ondeggia intorno" de Bernardo Tasso y se consagra para la poesía española con el soneto XXIII de Garcilaso, "En tanto que de rosa y d'azucena", y con el otro soneto, "Mientras por competir con tu cabello", compuesto por Góngora en 1582 a imitación de los anteriores. A partir de esos modelos, Espinel diseñó una relación inversa, no solo en los contenidos, sino incluso en la ordenación de los mismos. En efecto y por contraposición al ideal canonizado, esta dama es negra, hirsuta, seca, pálida y pelona, aunque, eso sí, tan severa como la más cabal belle sans merci que se precie. Pero es que, además, se consideran partes de su anatomía ajenas por completo a la decencia de la horma petrarquista, ya sea el pecho, las nalgas o el mismísimo sexo. Por si fuera poco, Espinel viene a marcar las distancias invirtiendo también la disposición retórica que el petrarquismo había establecido para el retrato de la donna angelicata. Si los sonetos antes mencionados se centraban en el rostro y solían hacer un recorrido descendente, esta bubosa se pinta de abajo a arriba, comenzando por los muslos para terminar con el cabello ausente y con la severidad del rostro. Tal alteración le sirve a Espinel para subrayar los intereses del rijoso enamorado, más atento a las leyes del gusto que a la proporción petrarquista a la hora de concebir la representación poética de su dama.

El gesto autobiográfico que enmarca ese retrato femenino es una baza más para sostener el realismo retórico y burlesco desde el que están escritos ambos poemas. El personaje de Espinel confiesa que, a pesar de su repugnante fealdad, esa dama bubosa le "abrasa el alma" y le "consume el pecho", convirtiendo el yo en referente cómico y encarnación de una paradoja amorosa y sexual. La explicación se ofrece en el epifonema que cierra el soneto, "iTal es la fuerza de un bellaco gusto!", por medio del cual el protagonista descubre a los lectores su incapacidad para resistirse al deseo carnal que le suscitan esa espantosa dama y sus bubas. Se trata de una suerte de dilema entre la pasión que produce en el amante la feísima bubosa y la certeza de que el morbo contagiado terminará por resultar incurable.

\footnotetext{
${ }^{6}$ Se ocupan de esta descripción Lara Garrido (1985: 29-30) y Garrote Bernal (1990: 191-192).
} 
Para Mateo Alemán, que poco después se convertiría autor del Guzmán de Alfarache, este soneto hubo de servirle como carta de presentación en los ambientes literarios del momento. El tema las bubas, por lo demás tan querido en la poesía satírica y burlesca de la Edad de Oro, compartía con la futura historia del pícaro el gusto por los ambientes prostibularios, la degradación moral de los protagonistas literarios e incluso el encomio ex contrario de lo que, en realidad, se pretendía censurar. Partiendo de la confesión hecha en el soneto de Espinel, el narrador de Alemán construye dos oraciones condicionales consecutivas que le sirven para pintar el cuerpo del enamorado, también deforme y cubierto de llagas, achacables tanto a la enfermedad como a unas curas terribles y continuadas "de otubre a otubre". En esa situación, el autor propone a su amigo buboso abandonar cualquier intento de cura y, ateniéndose a una suerte de estoicismo burlesco, reconocer su propia naturaleza, asumirla y dejarse llevar por el "bellaco gusto". Lejos de moralizar y reprehender el ayuntamiento carnal con la bubosa, el amigo se atiene a la máxima estoica del vivere secundum naturam, vivir conforme a la propia naturaleza, para aceptar no solo las bubas externas, sino también la internas que se mencionan en el verso 8 y que apuntan a esa paradójica pasión que ha dejado su huella en el alma. A un amante tan anclado en la lujuria solo le cabe aceptarse a sí mismo, por más que su condición de enamorado de una feísima mujer y su repetido contagio de bubas pudieran sorprender a los demás.

Los versos de Alemán resultan imprescindibles para resolver el problema planteado en el soneto de Espinel y para comprender la naturaleza retórica y cómica en este gesto de amistad literaria. Y es que, para empezar, el sevillano se atuvo a la misma disposición del original, comenzando por una descripción física a la que seguía una reflexión moral pareja a la articulada en el soneto correspondiente. No solo eso, en el poema "Si ese tu inútil cuerpo..." se lleva a cabo un fino ejercicio de ingenio y de escritura, pues Alemán subrayó el diálogo retórico entre ambos sonetos aviniéndose a utilizar como rima las mismas voces que había usado previamente el rondeño en similar posición entre cuartetos y tercetos. Estamos, pues, ante uno de esos entretenimientos poéticos que caracterizaron la vida de las academias literarias españolas, ya fuera en Valencia, en Granada, en la misma Sevilla nativa de Alemán o, claro está, a la corte. Los dos poemas pueden, además, relacionarse con un género de moda en el momento mismo de su composición, como es el encomio paradójico. Ese ejercicio retórico de abolengo lucianesco e intención festiva que tuvo un más que considerable arraigo en los ambientes literarios hispalenses de la segunda mitad del XVI y que tanto Espinel como Alemán habían de conocer, pues no en vano lo frecuentaron escritores contemporáneos como Juan de la Cueva, Luis Barahona

\footnotetext{
${ }^{7}$ Sobre ese estoicismo literario e histórico en Espinel, véase Díez Fernández (1993: 83-84).
} 
de Soto o Cristóbal Mosquera de Figueroa — todos sevillanos- y hasta el mismo Cervantes a su paso por Sevilla, si en verdad es el autor del romance en alabanza de las almorranas fechado en $1606^{8}$. De hecho, como ocurre en esos encomios paradójicos, los dos sonetos traen a primer plano una enfermedad marcada social y literariamente como las bubas y le añaden el aderezo de la fealdad exagerada de la amada, que, a pesar de lo evidente, termina imponiéndose como objeto jocoso de un amor tan risible como despreciable.

Además de ese factor ambiental, para urdir este juego, Espinel y Alemán pudieron encontrar un estímulo compositivo concreto en el epodo VIII de Horacio. No se olvide como argumento a favor de tal posibilidad que, si uno trasladó al castellano la Epistula ad Pisones y las odas I, 5 y III, 2 del poeta latino, el otro publicó un pliego suelto de Odas de Horacio, traducidas por Mateo Alemán con una versión de las odas 10 y 14 del libro II (Talavera Esteso, 1979). El epodo horaciano se consagra en su primera parte a la descripción física de una vieja libidinosa, de la que también se enumeran sus dientes negros, las arrugas en el rostro, unas escuálidas nalgas, el ano deforme, los pechos como ubres, el vientre flácido y los flacos muslos en términos parejos a los que hemos visto en Espinel:

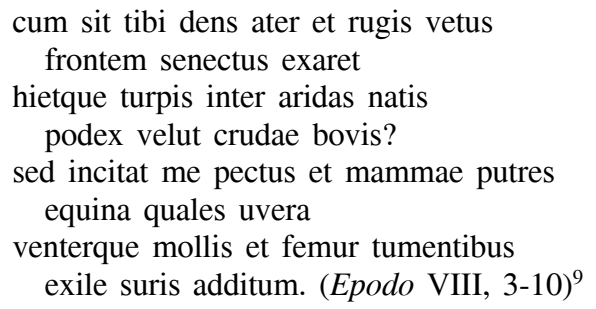

Pero si el antecedente horaciano no deja de ser una conjetura - aunque, a decir verdad, más que probable_-, los sonetos guardan una relación directa e indiscutible con un romance compuesto por Lope de Vega en 1591. Resulta que Luis de Góngora había hecho público ese mismo año su romance "A vos digo, señor Tajo", en el que se mofaba del río toledano (1998: I, 547-555). Lope se dio por ofendido y respondió al pronto con otro que comienza "Bien parece, padre Tajo" y que ha de leerse como ataque contra todo lo andaluz, aprovechando que el Guadalquivir pasaba por Córdoba y Sevilla ${ }^{10}$. En ese repa-

${ }^{8}$ En torno al género de los paradoxa encomia y su asiento en la literatura española del siglo XVI, véanse los estupendos e imprescindibles trabajos de Núñez Rivera (1998 y 2010).

${ }^{9}$ Sobre la conexión entre el poema de Espinel y el epodo horaciano, véase Cristóbal (1996: 240-241) y, sobre el propio texto latino y su tópica, Carrubba (1965) y Suárez Martínez (1994).

${ }^{10} \mathrm{El}$ poema se incluyó en el Ramillete de flores (1593: 130r) y apareció reimpreso al año siguiente en la Sexta parte de Flor de romances nuevos (1594). Respecto a este rifirrafe entre Góngora y Lope, 
so, Lope se detuvo a describir la fealdad de las damas andaluzas en términos muy próximos a los utilizados por Espinel para pintar a su bubosa enamorada:

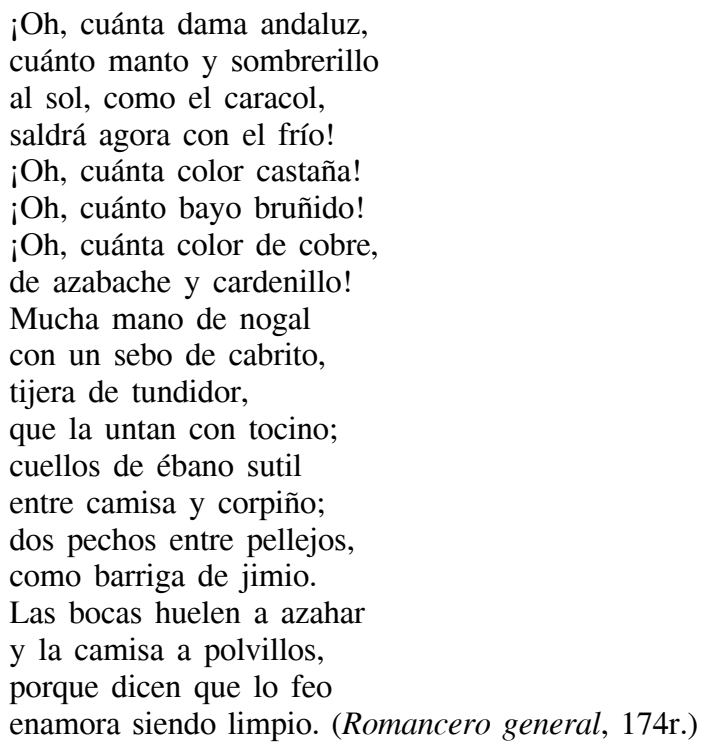

La "mano de nogal", el "ébano sutil", los "dos pechos entre pellejos" e incluso la referencia a "lo feo" que "enamora", traídos en un contexto poético similar, conforman un cúmulo suficiente de coincidencias como para poder asegurar sin margen de duda que ambos textos guardan entre sí una relación de dependencia. La dificultad estriba en establecer su prelación en el tiempo, pues no hay indicio alguno que permita hacerlo con seguridad. Me inclino, no obstante, a pensar que fue Lope de Vega quien, llevado por las premuras en responder a Góngora, pudo acudir a lo poco antes leído en los versos de Mateo Alemán y de Vicente Espinel, por más que ambos fueran andaluces. Sea como fuere, la proximidad entre el romance y los sonetos incidirían en la firme atribución de las piezas a Espinel y Alemán, ambos amigos próximos al Fénix, y en una fecha de composición no muy lejana a 1590 o 1591.

\section{UNA BREVE HISTORIA DE AMBOS TEXTOS}

El primero de los testimonios en que nos han llegado los sonetos, el cartapacio de Pedro Penagos, comenzó a compilarse en 1593 y ambos textos ocupan 
el folio 17 del códice $(A)$, lo que apuntaría a una fecha de traslado no muy posterior a ese momento. En el caso de Alemán - y hasta donde he podido llegar-, la transmisión manuscrita comienza y termina con esa copia, pues bien pronto el soneto de Espinel se desligó de su correspondiente y comenzó una larga vida independiente, primero manuscrita y luego impresa. Las Poesía varias conservadas en la British Library (Ms. Add. 10328) parecen tener una fecha de copia muy poco posterior, a finales del siglo XVI $(B)^{11}$, y lo mismo puede decirse de la Poesía española recopilada por Girolamo da Sommaia entre 1599 y 1607 y conservada en la Biblioteca Nazionale de Florencia $(C)^{12}$. El manuscrito Rime spagnuole de la Biblioteca Riccardiana, que recoge la versión atribuida a Padilla, está fechado por algún crítico en 1595, aunque la mayoría parece inclinarse por una copia de principios del XVII $(F)^{13}$. También pueden fecharse a principios de ese siglo - y, en concreto, después de 1602- las versiones del Codex 193 de la Universidad de Pennsylvania $(E)$ y el manuscrito Add. 18706 de la British Library $(D)^{14}$. A pleno siglo XVII parecen corresponder los manuscritos 3913 y 2244 de la Biblioteca Nacional de España $(G$ y $H)$, así como la versión del códice B2465, Tratado de las obras de don Luis de Góngora año del Señor de 1622 en Sevilla, perteneciente a la Hispanic Society of America y al final del cual se añadieron posteriormente y de otra mano una serie de sonetos, entre los que se encontraba el de Espinel $(I)^{15}$. Son, por último, copia del siglo XVIII las incluidas en la Colección de varias poesías manuscritas de los más célebres poetas de España $(J)$ y en el tomo III de las Obras manuscriptas de don Francisco de Quevedo y Villegas, caballero del Orden de Santiago $(K)$, conservadas manuscritas en la Biblioteca Nacional de España con las signaturas Ms. 3909 y Ms. $4067^{16}$.

Si el soneto de Mateo Alemán pasó casi desapercibido a los lectores contemporáneos, el de Vicente Espinel gozó, como puede comprobarse, de una larga vida manuscrita, que debió de ser mayor y variada, tal como se deduce del número y la complejidad de variantes textuales que se siguen de los once manuscritos conservados. Tan es así que, de entre esas copias de mano, las dos 306).

${ }^{11}$ Sobre la datación de este códice, véase Gayangos (1875: I, 17-25) y Ramos (2003-2004:

${ }^{12}$ Para este códice manuscrito Cl VII-354 NC/6, véase Cacho (2001: I, 65).

13 Propone la opción de 1595 Herrera Vázquez (2006: 410), mientras que al XVII apuntan Mele y Bonilla San Martín (1904: 168); Montero (1988: 61-65 y 2001: 305); y Cacho (2001: II, 496).

${ }^{14}$ En torno al manuscrito conservado en Pennsylvania, véanse los trabajos de Lasarte (1999 y 2002: 1083). Para la descripción y datación del códice británico, Catalogue of Additions (1868: 133) y Gayangos (1875: I, 25-30).

${ }^{15}$ Cfr. Inventario General (1984: 212-213 y 1962: 142-152) y Góngora (1981: 628).

${ }^{16}$ Cfr. Inventario General (1981: 211 y 257). 
más antiguas ya corresponden a tradiciones textuales bien distintas. A partir de ahí -y sin voluntad de formular stemma alguno_-, puede establecerse la existencia de familias distintas a $A$ y $B$, que han pervivido en copias posteriores. Así $F$ y $G$ son muestra de dos tradiciones independientes entre sí, pero ajenas por igual a $A$ y a $B$ y que sólo tienen continuidad en $K$, copiado a partir de $G$. El resto de testimonios mantiene lazos familiares con $A$; a pesar de lo cual, $C$ no siempre coincide con ese primer testimonio, $D$ ofrece una variante significativa en un verso problemático como el undécimo, $E$ incluye no pocas lecturas propias, $H$ se atiene con bastante fidelidad a su modelo, $I$ recoge un buen número de errores y lecturas que no hacen sentido y, en fin, $J$ aporta algunas pocas variantes con que ajustar la sintaxis de algunos pasajes.

La transmisión impresa del soneto comenzó en 1774, cuando López de Sedano (1774: 402) lo incluyó en el volumen VIII de su Parnaso español, atribuyéndoselo a Padilla y con unas variantes textuales que enlazan con la familia de $J$. Con toda probabilidad, Sedano fue la fuente de donde tomaron el poema Böhl de Faber (1823: 366) para la Segunda parte de la floresta de rimas antiguas castellanas y Antonio Marín Ocete (Laýnez, 1950: 361) para su edición de las Poesías de Pedro Laínez, aun cuando añadiera por su cuenta algunas malas lecturas. Benito Sánchez Alonso (1927: 418) editó el poema para discutir su atribución a Quevedo, por lo que su punto de partida fue el testimonio que hemos designado $K$, con las Obras manuscriptas de don Francisco de Quevedo y Villegas. Joaquín de Entrambasaguas (1951: 133-134) fue el primero en editar ambos sonetos, aprovechando para defender la atribución a Espinel. Su texto parte de $A$, pero introduce algunas variantes tan irrelevantes como impertinentes, fruto probable de una apresurada transcripción. A partir de ahí, todos los editores posteriores se han atenido a la pauta del cartapacio Penagos, aunque José Lara Garrido (Espinel, 1985: 111, 133 y 141) mantuviera algunas lecturas de Entrambasaguas. Por su parte, Gaspar Garrote (1990: 693) enmendó el verso 5 de Alemán para seguir la opción de $H$ y José J. Labrador y Ralph A. DiFranco (2012: 25), editores de la colección reunida por Penagos, han modernizado algunas voces.

Tanto en la edición de ambos sonetos que aquí se sigue como en los testimonios recogidos en el aparato crítico, se ha modernizado sistema ortográfico, aun cuando se haya optado por conservar las formas fonológicas originales. Los dos sonetos se acompañan de una anotación que intenta esclarecer su sentido literal y las muchas alusiones burlescas y satíricas que encierran. El aparato crítico es positivo y se abre con la lección por la que se ha optado. En él se recogen los estados y la transmisión del texto con todas las variantes que he sabido localizar y las explicaciones necesarias, aun cuando haya decidido prescindir en su registro de las cuestiones meramente ortográficas que no afectaban a la fonología ni al sentido. 


\section{EDICIÓN CRÍTICA}

\section{DE ESPINEL}

De un ébano sutil, dos bellas piernas -bellas del vello que las tapa y cubre-, una arrugada y descarnada ubre, dos secas nalgas y húmedas cavernas,

un pecho de tablón y dos mal tiernas castraduras de macho, que descubre dos brazos de nogal que, al mes de otubre, pronostican las cosas más internas,

un pálido color de quintangustia a puro azogue conservado y hecho y un listón en la frente atado al justo,

una severidad marchita y mustia me abrasa el alma y me consume el pecho. ¡Tal es la fuerza de un bellaco gusto!

\section{De Mateo Alemán, en Respuesta}

Si ese tu inútil cuerpo, brazos, piernas, con las más partes que el vestido cubre, tienes ya más flautadas que una ubre con fístolas, botanas y cavernas,

si estás lleno de gomas, y tan tiernas que cada cual revienta y nos descubre que, aunque te cures más de otubre a otubre, no aprovecha por ser bubas internas, ¿de qué te sirve ansiosa quintangustia desear ni intentar tan alto hecho?

Deja esta impresa y síguelo a tu gusto, que yo sé que la traes cansada y mustia, viendo la cuitadilla que en tu pecho cabe que el suyo tenga tan vil gusto.

\section{ANOTACIÓN}

\section{De Espinel}

1 ébano sutil: 'carne negra'. La fórmula también aparece en Tirso de Molina: "Golfo de ébano sutil / los cabos negros hacía / y al peine que los barría / llamó escoba de marfil” (1996: 249, vv. 2137-2140). Los dos primeros cuartetos describen la fealdad femenina en términos muy próximos a los que Lope de Vega utilizó para criticar a las mujeres andaluzas en el ro- 
mance "Bien parece, padre Tajo": "Mucha mano de nogal / con un sebo de cabrito, / tijera de tundidor, / que la untan con tocino. / Cuellos de ébano sutil / entre camisa y corpiño, / dos pechos entre pellejos, / como barriga de jimio. / Las bocas huelen a azahar / y la camisa a polvillos, / porque dicen que lo feo / enamora siendo limpio" (Romancero general, 1600: 174r).

2 Entiéndase que las piernas pueden ser hermosas solo porque están tapadas por la vellosidad, aunque también pueda apuntarse una alusión al vello púbico. El juego de homofonías entre bellas y vello parece tener su continuidad en el adjetivo bellaco que consta en el verso final del soneto.

3 Es muy posible que haya que interpretar ubre como metáfora descriptiva del estómago flácido, que también se registra en los versos 7-9 del epodo VIII de Horacio: "et mammae putres / equina quales uvera / venterque mollis".

4 Dada su enumeración junto a las nalgas y en plural, las húmedas cavernas han de entenderse como referencia al ano y al sexo femeninos.

5 un pecho de tablón: 'un pecho plano y duro'.

6 castraduras de macho: 'cicatrices hechas en un mulo', refiriéndose a los pechos y a los pezones mal tiernos, duros y secos. Debe advertirse que hay una concordancia ad sensum entre los dos sujetos pecho y castraduras y el verbo en singular descubre. Véase, en cualquier caso, el aparato crítico correspondiente a este verso.

7 brazos de nogal: 'brazos negros', como en el citado romance "Bien parece, padre Tajo": "Mucha mano de nogal" (Romancero general, 160: 174r). La medicina de la época consideraba el mes de octubre como el más apropiado para las curas de la sífilis, en las que se debía evitar el calor o el frío excesivos. Así se explica en el opúsculo del médico sevillano Jacinto Jiménez de Torres, Médica resolución en que se prueba ser el otoño tiempo conveniente para dar las unciones a los enfermos gálicos, Sevilla, s.i., 1646. Sobre esos períodos terapéuticos, véase Carmona García (2005: 247) y Valverde López (2009: 69-70).

8 pronostican las cosas más internas: 'descubren lo que se procura guardar en secreto', en este caso, el hecho de que la dama padece sífilis. Son los brazos los que hacen el pronóstico, puesto que se trataba de una zona visible y a la que habitualmente se aplicaba el mercurio como medio curativo.

9 quintangustia: 'dolor extremo', por alusión al quinto de los siete dolores de la Virgen, cuando contemplaba a Cristo en la cruz. La expresión se utilizó con frecuencia en la época para indicar un mal estado físico o anímico. Así, se lee en Luis del Milán (2001: I, 480): "La quinta angustia parezco / de muerto y descolorido" o en Góngora (1998: III, 281): "enfermo, amarillo y flaco, / como chupado de brujas, / por una que era entre todas / quinta esfera o quinta angustia". 
10 'provocado y mantenido por el tratamiento con mercurio', pues el azogue o mercurio era la cura más extendida para la sífilis, como recordaba Pedro de Torres en 1600 (1997: 27v): "remedio experimentado, cuando es la enfermedad de bubas, untar con el ungüento de azogue los hombros y nudos del cuello detrás de las orejas, hasta que comience a llagarse la boca".

11 listón: 'venda, cinta' con la que ocultar la pérdida de cabello provocada por la sífilis. La alopecia sifilítica era un síntoma común que menciona el propio Cervantes (2005: 534) en El casamiento engañoso: "Mudé posada y mudé el pelo dentro de pocos días, porque comenzaron a pelárseme las cejas y las pestañas, y poco a poco me dejaron los cabellos, y antes de edad me hice calvo, dándome una enfermedad que llaman lupicia, y por otro nombre más claro, la pelarela". El maestro Correas (1992: 371) recoge el refrán "Oír aquí y decir allí, eso hallaréis en mí; mas vendita por la frente, eso no", que explica como la ocultación de algo inconveniente: "Entiende venda por la frente o listón para encubrir cuchillada que dieron a una por mala y deslenguada".

12 severidad: 'rostro', por metonimia. También en El casamiento engañoso (Cervantes, 2005: 521) se señala la palidez de la cara como síntoma de la bubas y de su curación: "por la flaqueza de sus piernas y amarillez de su rostro, mostraba bien claro que, aunque no era el tiempo muy caluroso, debía de haber sudado en veinte días todo el humor que quizá granjeó en una hora”.

13 Tras ese me consume el pecho - y más allá de una tópica referencia a la pasión amorosa - cabe entender una mención tácita de las bubas trasmitidas por la dama y que también consumen al amante, como se desvelará en el soneto de respuesta.

14 bellaco gusto: 'bajo y perverso deleite, placer carnal'. De la dimensión sexual o rijosa del término bellaco queda rastro evidente en las Coplas sobre las pestíferas bubas del médico Francisco López de Villalobos (1948: 450): "Fue una pestilencia no vista jamás (...) / es muy gran bellaca, y así ha comenzado / por el más bellaco lugar que tenemos”, así como en el romancillo de Góngora (1998: I, 217-218) "Hermana Marica": "Bárbola, la hija / de la panadera, / la que suele darme / tortas con manteca, / porque algunas veces / hacemos yo y ella / las bellaquerías / detrás de la puerta" o en Tirso de Molina (1982: 222): "Amor y bellaquerías / que en Madrid y en huertas pasan, / tan célebres como esta".

\section{De Mateo Alemán, en respuesta}

1 No es casual que Alemán comience su respuesta con un ese de valor deíctico y anafórico, que viene a subrayar sintácticamente la interdepen- 
dencia entre los dos poemas. Esa conexión queda luego patente por el uso que aquí hace de las mismas voces que había utilizado previamente Espinel en similar posición de rima.

2 las más partes: 'las demás partes', en referencia a los órganos sexuales.

3 flautadas: 'desmejoradas', pero también 'agujereadas', como flautas, a causa de las purgas y curaciones. Téngase en cuenta que el adjetivo concuerda con "partes".

4 fístolas: 'llagas'; botanas: 'parches que se ponen en alguna llaga para que cure'; cavernas: 'heridas y agujeros en el cuerpo'.

5 gomas, y tan tiernas: 'tumores, y tan frescos y purulentos'.

7 'aunque siga el tratamiento contra las bubas durante más de un año completo'.

8 Esas bubas internas — frente a las visibles en el cuerpo- son los rastros que la lujuria deja en el ánimo del amante.

9 La ansiosa quintangustia debe interpretarse en relación con el sufrimiento y la congoja provocados por la purgación para curar las bubas. La voz ansiosa puede relacionarse jocosamente con el lenguaje de germanía, tan querido a Alemán y en el que ansia era sinónimo de 'tormento' o 'tortura'.

10 alto hecho: 'noble hazaña', que se sigue de la curación misma y del intento por abandonar el "bellaco gusto" mencionado en el último verso del primer soneto.

11 Deja esta impresa: 'Abandona esta empresa, renuncia a este acto esforzado y valeroso', para dejarte llevar por lo que te apetece, esto es, por el placer carnal.

12-14 Los tres últimos versos se mueven con una buscada ambigüedad que apunta, por un lado, a la dama sifilítica — aquí "cansada y mustia" frente al "marchita y mustia" del soneto de Espinel- y, por otro, al órgano sexual masculino, mencionado aquí en forma femenina. Lo que viene a decir, parafraseando los versos, es: 'porque yo sé que ella —dama y pene- está cansada y mustia, pues ve que tú puedes enamorarte de alguien que tiene un gusto tan vil como para enamorarse de ti', igualando finalmente la fealdad y la enfermedad de ambos amantes bubosos.

\section{APARATO CRÍTICO}

\section{TESTIMONIOS}

A: Soneto 76. De Espinel, en Poesías varias, Biblioteca Real (Madrid, España), Ms. II/1581(1), fol. 17r.

B: Soneto, en Poesías varias, British Library, Ms. Add. 10328, fol. 126. 
C: 38. Otro, en Poesía española, Biblioteca Nazionale (Florencia, Italia), Ms. $\mathrm{Cl}$ VII-354 NC/6, fols. 258v-259r.

D: Soneto, British Library, Ms. Add. 18706, fol. 122v.

E: Soneto, University of Pennsylvania Library, Ms. Codex 193, fol. 69v.

F: Soneto de Padilla, en Rime spagnuole, Biblioteca Riccardiana (Florencia, Italia), Ms. 3358 (a.3420), fol. 180r-v.

G: Otro, en Parnaso español. Libro de diferentes y varias poesías, Biblioteca Nacional de España, Ms. 3913, fol. 44v.

H: A una dama bubosa en quintaesencia, en Varios enigmas y versos, Biblioteca Nacional de España, Ms. 2244, fol. 15r-v.

I: De un ébano sutil, en Tratado de las obras de don Luis de Góngora año del Señor de 1622 en Sevilla, Hispanic Society of America, Ms. B2465, fol. 258r. Reproducido en Luis de Góngora, Sonetos, ed. Biruté Ciplijauskaité, Madison, Hispanic Seminary of Medieval Studies, 1981, p. 628.

J: Soneto. Colección de varias poesías manuscritas, Biblioteca Nacional de España, Ms. 3909, fol. 294v.

K: Soneto, Obras manuscriptas de don Francisco de Quevedo y Villegas, caballero del Orden de Santiago, tomo 3, Biblioteca Nacional de España, Ms. 4067, fol. $214 \mathrm{v}$.

Sed: Juan Joseph López de Sedano (1774: VIII, 402).

Fab: Juan Nicolás Böhl de Faber (1823: 366, n 666).

San: Benito Sánchez Alonso (1927: 418).

Oce: Antonio Marín Ocete (1950: 361).

Ent: Joaquín de Entrambasaguas (1951: I, 133-134).

Lar: José Lara Garrido (1985: 111, 133 y 141).

Gar: Gaspar Garrote Bernal (1990: 693).

Pen: José J. Labrador Herraiz, Ralph A. DiFranco y Abraham Madroñal (2012: 25).

\section{DE ESPINEL}

Título De Espinel A Ent Pen : Soneto de Padilla F : Otro CG : A una dama bubosa en quintaesencia $H$ : Soneto BDIJ : Pedro Laínez. Soneto inédito Sed : om. Fab San Oce Lar : Soneto [a una dama bubosa en quinta esencia] Gar [En $H$ se anota en el margen de otra mano: "En el Parnaso de Sedano VIII, p. 402, atribuido a $\mathrm{P}^{\circ}$ Laynez".

1 De un ébano sutil ABCHFGIJK Sed Fab San Oce Ent Lar Gar Pen : De un ébano subtil $D$ : De el ébano sutil $E$

2 que las tapa ABCDHEGIJK Sed Fab San Oce Ent Lar Gar Pen : que las ciñe $F$ 
3 una arrugada y descarnada ubre ADEHIJ Sed Fab Oce Ent Lar Gar Pen : con una aguda y descarnada ubre $B$ : con una descarnada y flaca ubre $C F$ : con una seca y descarnada ubre $G K$ San

4 dos secas nalgas y húmedas cavernas AHJ Sed Fab Oce Ent Lar Gar Pen: dos secas nalgas y húmidas cavernas $B C D E F$ : dos negras nalgas y húmidas cavernas $G K$ San : dos negras nalgas, húmidas cavernas $I$

5 un pecho de tablón y dos mal tiernas ACDJ Sed Fab Ent Lar Pen : un pecho de tablón con dos mal piernas $B$ : un pecho de tablón que dos mal tiernas $F$ : un pecho de tablón con dos mal tiernas $E H$ : un tablón de nogal, y dos mal tiernas GK San : un pecho de tablón con dos internas $I$ : un pecho de tablón y dos mil tiernas Oce : un pecho de tablón [con] dos mal tiernas Gar [Aun con una mala lectura evidente, $B$ ofrece una solución que evita el problema de concordancia y que luego recogen $E$ y $H$, enmendando su error. No obstante y dados los usos sintácticos del soneto, más bien parece intervención de un copista posterior dispuesto a corregir lo que considera un desliz. Por otro lado, hay que tener en cuenta que la concordancia ad sesum fue una alternativa frecuente en la sintaxis poética del Siglo de Oro, máxime cuando entraba en conflicto con la rima. Ante estos conflictos gramaticales, Gar anota su decisión de seguir la lección de $H$ "para hacer a pecho sujeto de descubre y mantener así la concordancia sintáctica".

6 castraduras de macho que descubre ABCDEHJ Sed Fab Oce Ent Lar Gar Pen : castraduras de macho nos descubre $F$ : mataduras de macho que descubre GIK San

7 dos brazos de nogal que, al mes de otubre ACD Ent Lar Gar : dos brazos de nogal que al mes de octubre BF Pen : dos secos brazos que en el mes de octubre $E$ : que allá en el erizado mes de otubre $G$ : dos brazos de nogal que el mes de octubre $H:$ dos brazos de nogal que el mes de otubre $I:$ que allá en el erizado mes de octubre $K$ San : un brazo de nogal que al mes de octubre $J$ Sed Fab Oce

8 pronostican las cosas más internas $A B D E G K$ San Ent Lar Gar Pen : pronostica las cosas más internas $C$ : nos descubre las cosas más internas $F$ : pronostican las causas más internas $H$ : pronostican las cosas más externas $I$ : pronostica las cosas más internas $J$ Sed Fab Oce

9 de quintangustia $A$ Ent Lar Gar Pen : de quinta angustia BCDEFGHIJK Sed Fab San Oce

10 conservado y hecho ABCDEGHJK Sed Fab San Oce Ent Lar Gar Pen : consumido y hecho $F$ : conservada y hecho $I$

11 y un listón en la frente atado al justo A Gar Pen : un listón a la frente atado al justo $B D$ : una severidad muy flaca y mustia $E$ : una veta a la frente atada al justo $F$ : un listón por la frente atado al justo HJ Sed Fab Oce : una cinta en la frente atada al justo $G$ San : un listón en la frente 
atado al justo $C I$ : una cinta a la frente atada al justo $K:$ y un listón en la frente atado a justo Ent Lar

12 una severidad marchita y mustia ABCFHJ Sed Fab Ent Lar Gar Pen : una severidad marchita y mustra $D$ : y un listón en la frente atado al justo $E$ : una arrugada cara fea y mustia GK San : una severidad machenta y nuestra $I$ : una severidad marchita, mustia Oce

13 me abrasa el alma ACDEIJ Sed Fab Oce Ent Gar Pen : me acaba el alma B : me enciende el alma $F$ : me abraza la alma $H$ Lar : esto me acaba $G K$ San

\section{DE MATEO ALEMÁN, EN RESPUESTA}

3 tienes ya más $A$ Lar Pen : tiene(s) ya más Ent

4 con fístolas, botanas $A$ : con fístolas botanas Pen : con fístolas batanas Ent Lar

9 ansiosa quintangustia $A$ Lar Pen : ansiosa quitangustia Ent

12 que yo sé que la traes $A$ Pen : que ya sé que la traes Ent Lar

\section{BIBLIOGRAFÍA}

AA. VV. (1593): Ramillete de flores. Cuarta, quinta y sexta parte de Flor de romances nuevos, Lisboa, Antonio Álvarez.

AA. VV. (1594): Sexta parte de Flor de romances nuevos, recopilados de muchos autores, Toledo, Pedro Rodríguez.

AA. VV. (1600): Romancero general en que se contienen todos los romances que andan impresos en las nueve partes de romanceros, Madrid, Luis Sánchez.

AA. VV. (1868): Catalogue of Additions to the Manuscripts in the British Museum in the Years 1848-1853, London, The British Museum.

AA. VV. (1962): Inventario General de Manuscritos de la Biblioteca Nacional. VI, Madrid, Ministerio de Cultura.

AA. VV. (1984): Inventario General de Manuscritos de la Biblioteca Nacional. X, Madrid, Ministerio de Cultura.

Alemán, Mateo (2012): Guzmán de Alfarache, Luis Gómez Canseco (ed.), Madrid, Real Academia Española.

Alonso Veloso, María José (2010): "Quevedo y Villegas, Francisco de: Poesía”, en Delia Gavela García, Pablo Jauralde García y Pedro C. Rojo Alique (coords.), Diccionario filológico de literatura española. Siglo XVII, Madrid, Castalia, I, pp. 136-173.,

Bajona Oliveras, Ignacio (1955-1956): "La amistad de Cervantes con Pedro de Padilla", Anales cervantinos, 5, pp. 231-241.

Böhl de Faber, Juan Nicolás (ed.) (1823): Segunda parte de la floresta de rimas antiguas castellanas, Hamburgo, Pertes y Besser.

Cacho, María Teresa (2001): Manuscritos hispánicos en las bibliotecas de Florencia, Firenze, Alinea Editrice.

Carmona García, Juan Ignacio (2005): Enfermedad y sociedad en los primeros Tiempos Modernos, Sevilla, Universidad de Sevilla. 
Carreira, Antonio (2002): "La poesía de Quevedo: textos interpolados, atribuidos y apócrifos", en Victoriano Roncero López y J. Enrique Duarte (coord.), Quevedo y la crítica a finales del siglo 20 (1975-2000), Pamplona, Universidad de Navarra, pp. 139-158.

Carrubba, Robert W. (1965): "A Study of Horace's Eighth and Twelfth Epodes", Latomus, 34, 1965, pp. 591-598.

Madroñal, Abraham, José Julián Labrador Herraiz y Ralph DiFranco (2012): Cartapacio de Pedro de Penagos, Guadalajara, Moalde.

Cervantes, Miguel de (2005): Novelas ejemplares, Jorge García López (ed.), Barcelona, Galaxia Gutenberg.

Correas, Gonzalo (1992): Vocabulario de refranes y frases proverbiales, Víctor Infantes (ed.), Madrid, Visor.

Cortijo Ortiz, Antonio (1995): "Inventario del Ms. II-1581 de la Biblioteca de Palacio de Madrid. El cartapacio de Pedro de Penagos", Reales Sitios: Revista del Patrimonio Nacional, 125, pp. $17-33$.

Cossío, José María de (1960): "Notas a romances", en Studia Philologica. Homenaje ofrecido a Dámaso Alonso, Madrid, Gredos, I, pp. 413-429.

Cristóbal, Vicente (1996): "Presencia de los clásicos latinos en la poesía de Vicente Espinel", Cuadernos de Filología Clásica. Estudios latinos, 11, pp. 235-254.

Díez Fernández, José Ignacio (1993): "Marcos de Obregón en tres epístolas de Vicente Espinel", Dicenda. Cuadernos de Filología Hispánica, 11, pp. 71-112.

Entrambasaguas, Joaquín (1950): "Datos biográficos de Vicente Espinel en sus Diversas rimas", Revista bibliográfica y documental, IV, pp. 171-243.

Entrambasaguas, Joaquín (1951): "Estudio preliminar", en Pedro Laýnez, Obras. I, Madrid, CSIC, pp. 1-364.

Espinel, Vicente (1985): Poesías sueltas, José Lara Garrido (ed.), Málaga, Diputación Provincial de Málaga.

Garrote Bernal, Gaspar (1990): La poesía de Vicente Espinel. Estudio y edición crítica, Madrid, Universidad Complutense de Madrid.

Garrote Bernal, Gaspar (2001): "Estudio preliminar", en Vicente Espinel, Diversas rimas, Málaga, Diputación Provincial de Málaga, pp. 11-395.

Gayangos, Pascual de (1875): Catalogue of the Manuscripts in the Spanish Language in the British Museum, London, The British Museum.

Góngora, Luis de (1981): Sonetos, Biruté Ciplijauskaité (ed.), Madison, Hispanic Seminary of Medieval Studies.

Góngora, Luis de (1998): Romances, Antonio Carreira (ed.), Barcelona, Quaderns Crema.

Haley, George (1994): "Vicente Espinel y Marcos de Obregón: biografía, autobiografía y novela", en José Lara Garrido (coord.), Vicente Espinel, Obras completas: Introducción general, Málaga, Diputación Provincial de Málaga.

Herrera Vázquez, Manuel (2006): "Notas sobre la recopilación y organización de materiales en los cancioneros de poesías varias del último tercio del siglo XVI", en Vicenç Beltrán y * Juan Paredes Núñez (eds.), Convivio: estudios sobre la poesía de cancionero, * Granada, Universidad de Granada, pp. 375-418.

Jiménez de Torres, Jacinto (1646): Médica resolución en que se prueba ser el otoño tiempo conveniente para dar las unciones a los enfermos gálicos, Sevilla, s.i.

Lara Garrido, José (1985): "Introducción”, en Vicente Espinel, Poesías sueltas, Málaga, Diputación Provincial de Málaga, pp. 7-40.

Lasarte, Pedro (1999): "Hacia un estudio del cancionero poético 'Ms. Codex 193' de la Universidad de Pensilvania", en Ignacio Arellano y José Antonio Rodríguez Garrido (eds.), Edición y anotación de textos coloniales hispanoamericanos, Madrid-Frankfurt, IberoamericanaVervuert, pp. 233-244. 
Lasarte, Pedro (2002): "Una glosa inédita del novohispano José de Arrázola y algunas variantes mexicanas desconocidas a las obras de González de Eslava y Gutierre de Cetina", en Eduardo Hopkins Rodríguez (ed.), Homenaje a Luis Jaime Cisneros, Lima, Pontificia Universidad Católica del Perú, II, pp. 1081-1099.

Laýnez, Pedro (1950): Poesías, Antonio Marín Ocete (ed.), Granada, Universidad de Granada. López de Sedano, Juan Joseph (1774): Parnaso español. VIII, Madrid, Joaquín de Ibarra.

López de Villalobos, Francisco (1948): El sumario de la medicina, con un tratado sobre las pestíferas bubas, Eduardo García del Real (ed.), Madrid, Real Academia de Medicina.

Madroñal, Abraham (2012): "Entre Cervantes y Lope: Toledo, hacia 1604", eHumanistal Cervantes, 1, pp. 300-332.

Mele, Eugenio y Adolfo Bonilla San Martín (1904): "Dos cancioneros españoles", Revista de Archivos, Bibliotecas y Museos, X, pp. 162-176 y pp. 408-417.

Milán, Luis del (2001): El cortesano, Vicent-Josep Escartí (ed.), Valencia, Universitat de València-Ajuntament de València, 2 vols.

Millé y Giménez, Juan (1933): "Miscelánea lopista", Revista de la Biblioteca, Archivo y Museo del Ayuntamiento de Madrid, X, pp. 241-248.

Montero, Juan (1988): "La Sátira contra la mala poesía del canónigo Pacheco: una coda bibliográfica", Manuscrt.Cao, IV, pp. 61-65.

Montero, Juan (2001): "Problemas textuales en la Sátira del licenciado Pacheco (Primera entrega)", en Rogelio Reyes Cano, * Mercedes de los Reyes Peña y Klaus Wagner (coord.), Sevilla y la Literatura: Homenaje Al Profesor Francisco López Estrada en su 80 cumpleaños, Sevilla, Universidad de Sevilla, pp. 303-314.

Núñez Rivera, Valentín (1998): "Para la trayectoria del encomio paradójico en la literatura española del Siglo de Oro. El caso de Mosquera de Figueroa", en María Cruz García de Enterría y Alicia Cordón Mesa (coord.), Actas del IV Congreso Internacional de la Asociación Internacional Siglo de Oro (AISO). Alcalá de Henares, 22-27 de Julio de 1996, Alcalá de Henares, Universidad de Alcalá, pp. 1133-1143.

Núñez Rivera, Valentín (2010): "Para la tradición del género paradójico", en Cristóbal Mosquera de Figueroa, Paradojas: Paradoja en loor de la nariz muy grande. Paradoja en loor de las bubas, Salamanca, Universidad de Salamanca, pp. 15-109.

Orozco Díaz, Emilio (1973): Lope y Góngora frente a frente, Madrid, Gredos.

Padilla, Pedro (2007): Cancionero autógrafo de Pedro Padilla. Manuscrito 1597 de la Biblioteca Real de Madrid, ed. José J. Labrador Herraiz y Ralph A DiFranco, México, Frente de Afirmación Hispanista.

Padilla, Pedro (2009): Cancionero de Pedro de Padilla, con algunas obras de sus amigos. Manuscrito 1587 de la Biblioteca Real de Madrid, José Manuel Pedrosa, José J. Labrador Herraiz y Ralph A. DiFranco (eds.), México, Frente de Afirmación Hispanista.

Quevedo, Francisco de (1969): Obra poética. I, José M. Blecua (ed.), Madrid, Castalia.

Ramos, Rafael (2003-2004): "El cancionero castellano de Ripoll: una rara colección poética de finales del siglo XVI", Boletín de la Real Academia de Buenas Letras de Barcelona, 49, pp. 249-316.

Rey Hazas, Antonio (2005): Poética de la libertad y otras claves cervantinas, Madrid, Eneida.

Rico García, José Manuel y José Solís de los Santos (2008): "La sonetada a Lope del Cartapacio de Palomo", Anuario Lope de Vega, XIV, pp. 235-268.

Sánchez Alonso, Benito (1927): "Las poesías inéditas e inciertas de Quevedo", * Revista de la Biblioteca, Archivo y Museo, del Ayuntamiento de Madrid, 4, pp. 123-146 y 387-431., ,

Suárez Martínez, Pedro M. (1994): "Horacio y las viejas libidinosas", Estudios clásicos, 105, pp. 49-62.

Talavera Esteso, Francisco J. (1979): "Vicente Espinel, traductor de Horacio", en AA. VV. Estudios sobre Vicente Espinel, Málaga, Universidad de Málaga, pp. 69-101. 
Tirso de Molina (1982): La huerta de Juan Fernández, Berta Pallares (ed.), Madrid, Castalia. Tirso de Molina (1996): Celos con celos se curan, Blanca Oteiza (ed.), Kassel, Reichenberger. Torres, Pedro de (1997): Libro que trata de la enfermedad de las bubas, María Teresa Herrera y María Estela González de Fauve (ed.), Madison, Hispanic Seminary of Medieval Studies.

Valladares Reguero, Aurelio (2008): "La poesía epistolar de Pedro de Padilla", en José Lara Garrido (ed.), La epístola poética del Renacimiento español, Málaga, Universidad de Málaga, pp. 297-327.

Valladares Reguero, Aurelio (2010): Pedro de Padilla. Una singular aportación giennense a la poesía española del siglo XVI, Jaén, Universidad de Jaén.

Valverde López, José Luis (2009): Los servicios farmacéuticos del Hospital de los Reyes, Granada, Universidad de Granada.

Fecha de recepción: 25 de abril de 2013

Fecha de aceptación: 25 de septiembre de 2013 